Nuclear Science and Technology Division

\title{
RESULTS OF DEPOSITION SCOPING TESTS
}

M. Z. Hu, D. W. DePaoli, and A. J. Mattus

Date Published: February 2003

Prepared by

OAK RIDGE NATIONAL LABORATORY

Oak Ridge, Tennessee 37831-6254

managed by

UT-BATTELLE, LLC

for the

U.S. DEPARTMENT OF ENERGY

under contract DE-AC05-00OR22725 



\section{CONTENTS}

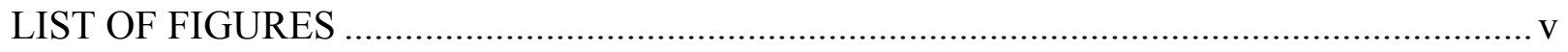

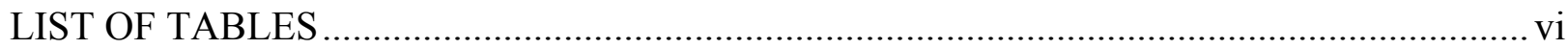

ACRONYMS AND NOMENCLATURE ...................................................................... vii

EXECUTIVE SUMMARY ..........................................................................................

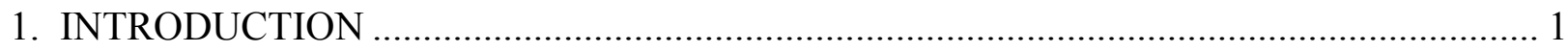

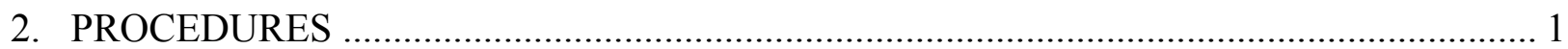

2.1 EXPERIMENT SET ONE - [AL]:[SI] = 1, WITHOUT VOLUME

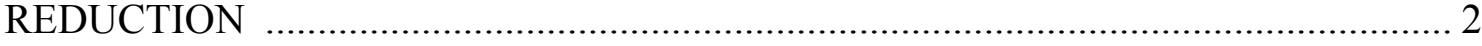

2.2 EXPERIMENT SET TWO - [AL]:[SI] > 1, WITH VOLUME REDUCTION

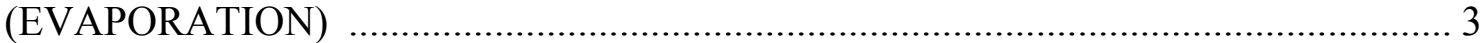

2.2.1 Preparation of 2H Evaporator Simulants and Resulting Mixture

Compositions Tested .......................................................................... 3

2.2.2 Preparation of 3H Evaporator Simulant..................................................... 4

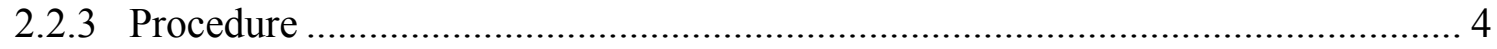

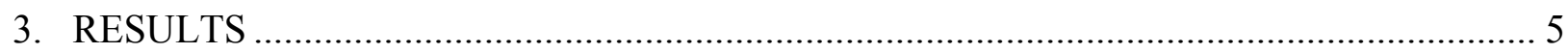

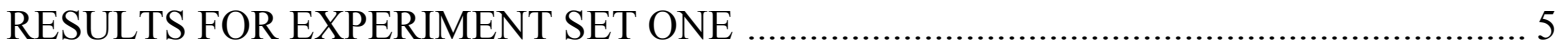

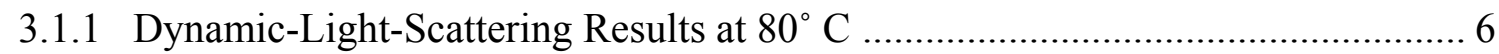

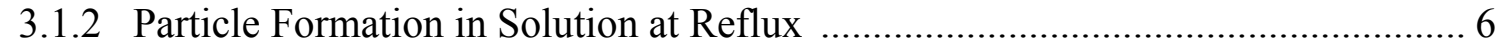

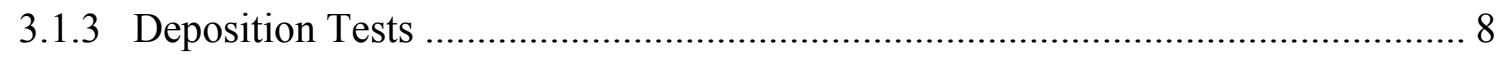

RESULTS FOR EXPERIMENT SET TWO ............................................................... 12

3.2.1 Tests with 2H Evaporator Simulants and Resulting Mixture Compositions ......... 12

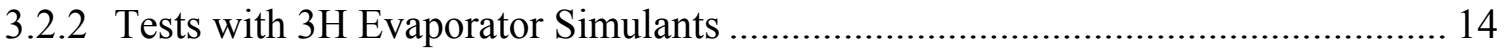

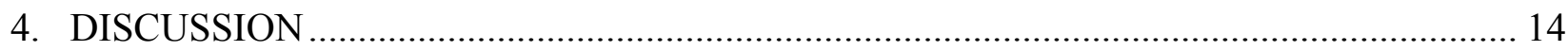

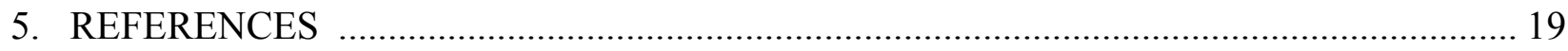





\section{LIST OF FIGURES}

1 Apparatus used for refluxing of simulant solutions for particle formation and deposition tests

2 Position of stainless steel coupons in stirred beaker for batch evaporation tests..... 5

3 Dynamic-light-scattering results for $0.04 \mathrm{M}$ and $0.03 \mathrm{M \ldots \ldots \ldots \ldots \ldots \ldots \ldots \ldots \ldots \ldots \ldots \ldots \ldots \ldots \ldots \ldots \ldots \ldots \ldots \ldots \ldots \ldots \ldots \ldots \ldots \ldots \ldots \ldots \ldots \ldots}$

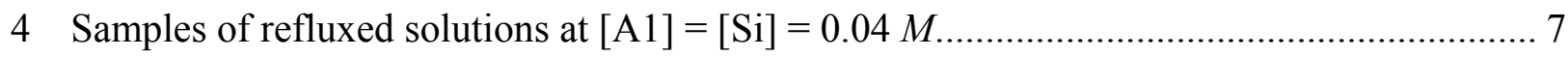

5 SEM images of solids from $0.04 M$ experiment at reflux ......................................... 8

6 Samples from reflux experiments at lower supersaturation .......................................... 9

7 Samples of stainless steel foil after 4-h reflux experiments tests ................................... 10

8 SEM images of metal surfaces from 4-h refluxed deposition tests ................................ 11

9 SEM images of solids deposited on metal surfaces during 4-h refluxed deposition tests ....... 12

10 SEM images of solids on the surfaces of stainless steel coupons immersed in solutions

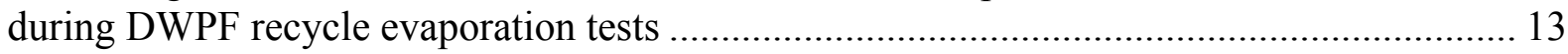

11 SEM images of solids on the surfaces of stainless steel coupons immersed in solutions

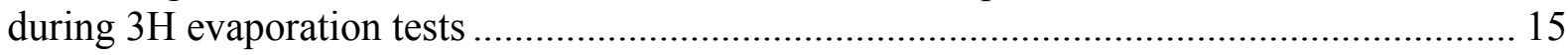

12 SEM images of macroscopic solids deposits from $32 \%$ evaporation of $3 \mathrm{H}$ simulant tests ... 16 


\section{LIST OF TABLES}

1 Compositions of Tank 43 and DWPF simulants....................................................... 3

2 Composition of Tank 43/DWPF solutions tested .................................................. 4

3 Diluted Tank 30 simulant composition.................................................................... 4

4 Induction-time measurements at $80^{\circ} \mathrm{C}$ by dynamic light scattering ................................. 6

5 Results of particle formation test under reflux at $0.04 \mathrm{M}$ aluminum and silicon................... 7

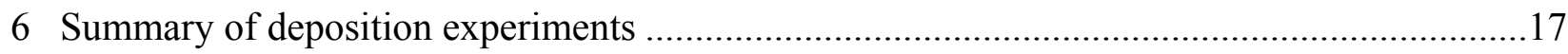





\section{ACRONYMS AND NOMENCLATURE}

DLS dynamic light scattering

DWPF Defense Waste Processing Facility

EDS energy dispersion spectroscopy

$K_{s p} \quad$ solubility product constant

NAS sodium aluminosilicate

PTFE polytetrafluorethylene

$Q(N A S) \quad$ ion product (reaction quotient) for sodium aluminosilicate

SEM scanning electron microscopy

SRS Savannah River Site 



\section{EXECUTIVE SUMMARY}

The processes of crystallization and solid deposit formation that led to the shutdown of $2 \mathrm{H}$ evaporator operation at the Savannah River Site (SRS) and that could possibly cause similar problems in the future or in other evaporators need to be better understood. Deposition scoping tests, described by Task E-1 of the Oak Ridge Technical Task Plan (TTP) OR-16WT41, have been conducted to provide information that can be used in defining acceptable levels of silicon and aluminum in evaporator feed solutions. The objective of these scoping tests was to determine the minimum supersaturation level at which the formation of solids is detectable under the temperature and residence time conditions of the evaporator operation. This report, which fulfills Savannah River Task SR ID 2HDSTT0045, describes the experiments conducted to date, discusses the results relative to other ongoing work related to the problem, and makes recommendations for future work based upon the results.

Laboratory studies of solids formation were conducted using simulant solutions at relatively low levels of supersaturation for aluminum and silicon. These batch scoping tests were designed to determine the minimum supersaturation level at which the formation of particles in solution and on steel surfaces is detectable under temperature and residence-time conditions similar to those of evaporator operation. The results of this work showed that the formation of solids in solution at a 1:1 concentration ratio of silicon to aluminum is thermodynamically and kinetically favorable under evaporator conditions at concentrations as low as $K_{s p}$ (or solubility product constant $)=[\mathrm{Al}][\mathrm{Si}]=6 \times 10^{-4} \mathrm{M}^{2}$. At the lower concentrations tested $(<0.025 \mathrm{M}$ aluminum and silicon), no solids were detected at elevated temperature; however, sols (i.e., diluted suspension of colloids) formed upon cooling of the solution. In addition to formation of solids in solution, three sets of experiments at varying aluminum-to-silicon concentration ratios were conducted in which aluminosilicate solids were grown heterogeneously on steel surfaces. Macroscopic amounts of solids were deposited at $0.04 \mathrm{M}$ aluminum and silicon-concentrations lower than a recently proposed control level of the product $[\mathrm{Al}][\mathrm{Si}]=2.3 \times 10^{-3} \mathrm{M}^{2}$. Additional experiments conducted in conjunction with Defense Waste Processing Facility recycle evaporation tests at higher aluminum-to-silicon concentration ratios generated microscopic solids under nearly all concentrations tested; however, macroscopic quantities of solids were detected in only one portion of one sample. The results obtained to date in these laboratory-scale batch tests suggest that the silicon and aluminum concentration levels above which aluminosilicate solids may form under evaporator conditions may be lower than those described by the product [A1][Si] and/or the $Q$ (ion product) values for sodium aluminosilicate currently used as the operational limit. However, because only microscopic quantities of solids were formed on the stainless steel coupons in the majority of the batch experiments and significant plant data exists for acceptable operation in those concentration regimes, it is possible that evaporators may be acceptably operated under conditions that form solids in laboratory experiments. Further experimentation, including continuous-flow evaporator tests, is recommended to help define evaporator operational limits. 


\section{INTRODUCTION}

The processes of crystallization and solid deposit formation that led to the shutdown of the $2 \mathrm{H}$ evaporator operation at the Savannah River Site (SRS) and that could possibly cause similar problems in the future or in other evaporators need to be better understood. Through experimentation, thermodynamic modeling, and correlation of scaling to historical tank farm operations, progress has been made in developing guidelines as to the concentrations of silicon and aluminum that can be processed by evaporators while avoiding unacceptable levels of scale formation. However, because of limitations of the thermodynamic model and an insufficient amount of operational data at slightly supersaturated concentration levels, uncertainty still exists regarding acceptable feed concentrations.

The objective of this effort is to provide information that can be used in defining acceptable levels of silicon and aluminum in evaporator feed solutions. Data collected previously showed that particle formation reactions can be rapid at evaporator temperatures for elevated silicon and aluminum concentrations. However, insufficient data exists to estimate the silicon and aluminum concentrations above which solids will form in the time frame of evaporator processing. The work described in this report was designed to determine the induction period for solutions of decreasing aluminum and silicon concentration such that the supersaturation level corresponding to a 4-h induction time for particle nucleation/growth in bulk solution can be estimated. In addition, experiments were conducted to explore the supersaturation levels that can result in deposition of solids on metal surfaces at varying aluminum-to-silicon concentration ratios.

Laboratory studies of particle growth in solution were conducted at relatively low supersaturation levels. Dynamic-light-scattering (DLS) studies and deposition tests, similar to those performed in FY 2001, were conducted with solutions at relatively low supersaturation levels and at elevated temperatures to explore the formation of solids under conditions similar to those encountered in evaporator processing. The deposition of solids on stainless steel samples placed in the solutions during the experiments was simultaneously investigated. In addition, the deposition of solids on stainless steel surfaces was investigated in laboratory-scale batch evaporation experiments.

Completion of this effort will aid the development of operating strategies to mitigate or avoid solid scale formation on surfaces in evaporator systems. The results are expected to benefit plant operations by helping to determine acceptable silicon and aluminum feed concentrations.

\section{PROCEDURES}

Two sets of experiments were conducted - one with no volume reduction using solutions having a 1:1 ratio of silicon to aluminum concentration and the other involving volume reduction by evaporation of solutions having aluminum-to-silicon concentration ratios greater than 1 . 


\subsection{EXPERIMENT SET ONE - [AI]:[Si] = 1, WITHOUT VOLUME REDUCTION}

DLS measurements were conducted for solutions of varying silicon and aluminum concentration for the purpose of measuring induction time for detectable particle formation under conditions simulating those in the $2 \mathrm{H}$ evaporator. The tests were conducted in $6 \mathrm{M} \mathrm{OH}^{-}$and $1.5 \mathrm{M}$ each of nitrate and nitrite anions, rather than the $4 \mathrm{M} \mathrm{OH}^{-}$and $1 M$ nitrate/nitrite levels used previously), ${ }^{1}$ in order to more closely match the evaporator conditions under reflux of solution. The solutions used in the tests had a constant [Si]:[Al] ratio of 1.0; the level of supersaturation was varied by changing the concentrations of silicon and aluminum by the same amount. Solution preparation is described in the Appendix.

DLS scoping experiments were initially conducted at $80^{\circ} \mathrm{C}$ in order to minimize the number of experiments conducted at elevated temperature. The tests were conducted as described in ORNL/TM-2001/100. ${ }^{1}$ Aluminum and silicon concentrations were tested starting at $0.05 \mathrm{M}$ and then decreased, with concentrations and sampling times for each test to be defined based on the results of previous tests. At each supersaturation level, real-time DLS was used for automatic data collection to determine the induction time at $80^{\circ} \mathrm{C}$. Such data, coupled with the activation energy determined previously, could be useful to estimate the induction times at higher temperatures at a particular supersaturation level.

Experiments were then conducted at elevated temperatures, using the reflux apparatus shown in Fig. 1. Preheated base simulant plus aluminum source was added to a Teflon ${ }^{\circledR}$ reaction vessel. The vessel was capped before being placed into a heated silicone oil bath. The bath was thermostated to maintain the temperature of the base simulant $(\sim 200 \mathrm{~mL})$ at conditions of gentle boiling $\left(\sim 115^{\circ} \mathrm{C}\right)$. The cap of the vessel was fitted with a water-jacketed condenser that is open to the atmosphere to minimize concentration of the simulant by evaporation during the 4-h test interval. A magnetically driven Teflon ${ }^{\circledR}$-coated stir bar was used to maintain homogeneity of the simulant.

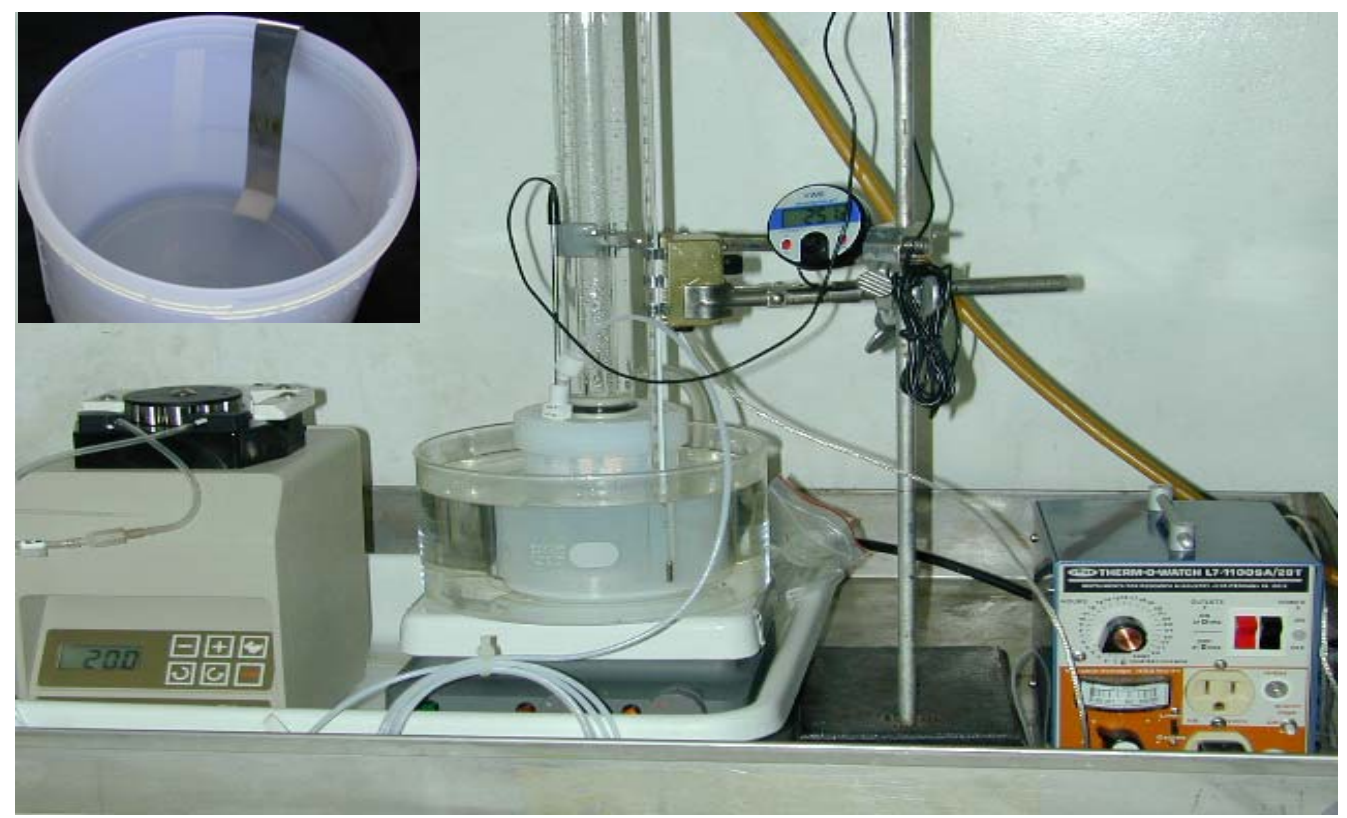

Fig. 1. Apparatus used for refluxing of simulant solutions for particle formation and deposition tests. The inset photograph shows the position of foil in deposition tests. 
Varying volumes of preheated silicon concentrates were injected through a third port in the vessel cap. This same port was used to place a stainless steel thermometer probe into the vessel to measure the temperature of the test solution. Intermittent sampling of the test solution was achieved by inserting the lead end of a Teflon ${ }^{\circledR}$ sampling loop into this port. Test solution was withdrawn from the vessel by activating a peristaltic pump connected to the exit end of the sampling loop. The Teflon ${ }^{\circledR}$ tubing was then removed from the vessel and slipped into a cuvette, and the operation of the peristaltic pump was reversed to fill the cuvette cell. The sampling port was sealed when solution addition or sample withdrawal was not taking place.

\subsection{EXPERIMENT SET TWO - [A1]:[Si] > 1, WITH VOLUME REDUCTION (EVAPORATION)}

A second set of deposition scoping tests was conducted. In these tests, the formation of solids on stainless steel coupons was investigated in conjunction with the determination of formation of solids in bulk solution in Defense Waste Processing Facility (DWPF) recycle evaporation experiments. Solutions of two types were used in these experiments-(1) simulants representing different mixtures of SRS Tank 43 waste and DWPF recycle as $2 \mathrm{H}$ evaporator feed and (2) a simulant of SRS Tank 30 feed to the $3 \mathrm{H}$ evaporator.

\subsubsection{Preparation of $2 \mathrm{H}$ Evaporator Simulants and Resulting Mixture Compositions}

Two different simulants representing SRS Tank 43 waste and DWPF recycle waste were prepared. Table 1 presents the composition of these simulants.

\section{Table 1. Compositions of Tank 43 and DWPF simulants ${ }^{\mathrm{a}}$}

\begin{tabular}{lll}
\hline \multicolumn{1}{c}{ Species } & $\begin{array}{c}\text { DWPF simulant } \\
(\mathrm{mol} / \mathrm{L})\end{array}$ & $\begin{array}{c}\text { Tank 43 simulant } \\
(\mathrm{mol} / \mathrm{L})\end{array}$ \\
\hline Sodium & 0.96 & 3.59 \\
Aluminum & 0.0 & 0.070 \\
Silicon & 0.0023 & 0.0014 \\
Hydroxide (free) & 0.50 & 2.00 \\
Carbonate & 0.074 & 0.0 \\
Nitrate & 0.06 & 0.50 \\
Nitrite & 0.25 & 1.00 \\
\hline
\end{tabular}

${ }^{\mathrm{a}}$ The densities of the DWPF and Tank 43 simulants at $22^{\circ} \mathrm{C}$ were 1.04 and $1.15 \mathrm{~g} / \mathrm{mL}$, respectively.

These two simulants were then combined at the desired volumetric ratios for use in the evaporation tests. The compositions for the designated ratios of Tank 43 to DWPF solution are listed in Table 2. The resulting composition was produced at time zero prior to evaporation. 
Table 2. Composition of Tank 43/DWPF solutions tested

\begin{tabular}{|c|c|c|c|}
\hline \multirow[b]{2}{*}{ Species } & \multicolumn{3}{|c|}{ Concentration (mol/L) for different T43:DWPF ratios } \\
\hline & $26: 74$ & 39:61 & $63: 37$ \\
\hline Sodium & 1.65 & 1.98 & 2.58 \\
\hline Aluminum & 0.018 & 0.027 & 0.044 \\
\hline Silicon & 0.0019 & 0.0018 & 0.0017 \\
\hline Hydroxide (free) & 0.89 & 1.09 & 1.45 \\
\hline Carbonate & 0.174 & 0.232 & 0.337 \\
\hline Nitrate & 0.445 & 0.543 & 0.723 \\
\hline Nitrite & 0.056 & 0.046 & 0.028 \\
\hline
\end{tabular}

\subsubsection{Preparation of $3 H$ Evaporator Simulant}

A simulant of $3 \mathrm{H}$ feed was prepared based upon data presented in SRT-LWP-2002-00053 for three samples of Tank 30 waste taken in January of 2002. Because of the high alkalinity, a 50\% caustic solution was used in the preparation. Sodium aluminate and sodium silicate were used as the sources of aluminum and silicon, respectively, in addition to sodium salts of nitrate and nitrite. The final simulant was found to have a density of $1.45 \mathrm{~g} / \mathrm{mL}$. Table 3 presents the starting composition of the $3 \mathrm{H}$ simulant that was evaporated; this solution was prepared so that it was approximately $12 \%$ more dilute than the average value obtained for the Tank 30 sample analyses. This dilution provides time at temperature for evaporation of the solution to the Tank 30 concentration.

Table 3. Diluted Tank 30 Simulant Composition

\begin{tabular}{lc}
\hline \multicolumn{1}{c}{ Species } & $\begin{array}{c}\text { Concentration } \\
(\mathrm{mol} / \mathrm{L})\end{array}$ \\
\hline $\mathrm{NaOH}$ & 8.50 \\
$\mathrm{Na}_{2} \mathrm{SiO}_{3} \cdot 5 \mathrm{H}_{2} \mathrm{O}$ & 0.0021 \\
$\mathrm{NaAlO}_{2} \cdot 2 \mathrm{H}_{2} \mathrm{O}$ & 0.800 \\
$\mathrm{NaNO}_{3}$ & 1.2 \\
$\mathrm{NaNO}$ & 1.50 \\
$\mathrm{Na}$ (total) & 12.0 \\
\hline
\end{tabular}

\subsubsection{Procedure}

Evaporation tests were performed in $600-\mathrm{mL}$ stainless steel (304) beakers placed inside a silicone oil bath with temperature control to $0.1^{\circ} \mathrm{C}$. A starting volume of $450 \mathrm{~mL}$ of solution was used in all tests. In tests that employed the $3 \mathrm{H}$ stimulant, the full volume of stimulant was added in one part, with the sodium silicate from a $2-\mathrm{mL}$ solution added at time zero. Tests with $2 \mathrm{H}$ stimulant mixtures were added in two parts, representing DWPF and Tank 43 simulant, respectively, to obtain the desired volumetric mixture ratio of the two simulants.

A polyethylene-coated mixing propeller with motor-boat-type blade was placed in the center of the vessel, $1 \mathrm{~cm}$ from the bottom of the container. A mixing motor with rpm display was attached and used in all tests, with a fixed speed of $250 \mathrm{rpm}$. To eliminate the uptake of carbon dioxide from the atmosphere, nitrogen gas was slowly bled into each vessel for the full duration of each test. A stainless steel sheet was cut into coupons or strips. The bottom of each coupon was bent into the shape of an "el," and a stainless steel capillary tube was then attached along its 
length to make it more rigid. These coupons were placed along the inside wall of the evaporation vessels so that the horizontal portion of the end of the coupon was just above the mixing propeller and in the same plane as the propeller (see Fig. 2). Each coupon could be removed separately at the desired sampling time, at which time it was vigorously rinsed in deionized water and then viewed by scanning electron microscopy (SEM) to look for aluminosilicate formation on its horizontal surface.

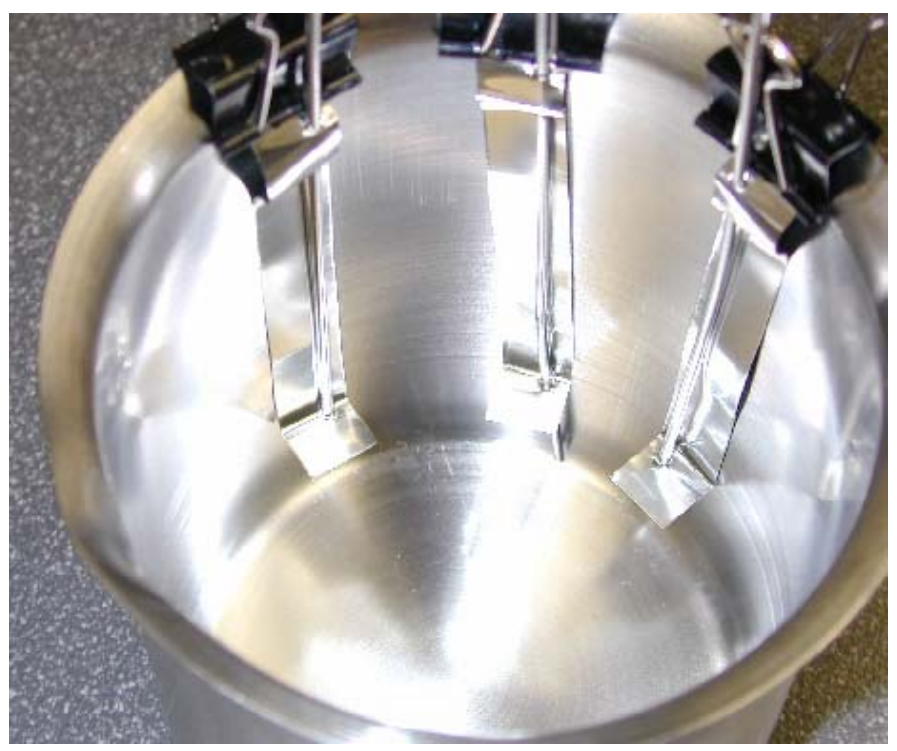

Fig. 2. Position of stainless steel coupons in stirred beaker for batch evaporation tests.

In order to determine the amount of water evaporated from each test vessel as a function of time, a conductivity-based device was fabricated to track the decreasing level of simulant in the vessel. A circuit-comprising a 6-volt battery, a light-emitting diode, and wires, with a sliding stainless tube that was raised and lowered to make contact with the upper surface of the solutionpermitted accurate assessment of the solution remaining inside the vessel. A calibration curve was prepared via this device using a salt solution. This curve was used in both tests with $2 \mathrm{H}$ simulant and in the single $3 \mathrm{H}$ evaporation test.

Three different mix ratios were used for evaporation tests of Tank 43 and DWPF simulants: 26:74, 39:61, and 63:37 (Tank43/DWPF) by volume. Planned sampling times were at 66, 80 and $90 \%$ evaporation points. For the single evaporation test with $3 \mathrm{H}$ simulant, the planned sampling points were at volume reductions from the diluted starting solution of 14, 40, 49 and 56\%, which would correspond to $0,32,40$, and $48 \%$ evaporation from averaged $3 \mathrm{H}$ feed composition. Samples were taken at points corresponding to 0,32 , and $42 \%$ evaporation of $3 \mathrm{H}$ feed.

\subsection{RESULTS}

\subsection{RESULTS FOR EXPERIMENT SET ONE}

For the first set of experiments ([A1]:[Si] = 1 without volume reduction), results of three types are reported: 
- DLS results at $80^{\circ} \mathrm{C}$,

- Particle formation in solution at reflux, and

- Solids deposition from refluxing solution.

\subsubsection{Dynamic-Light-Scattering Results at $80^{\circ} \mathrm{C}$}

Initial experiments were conducted via in situ monitoring of nucleation of solid particles in bulk solution at $80^{\circ} \mathrm{C}$ using DLS. Representative results are shown in Fig. 3 for aluminum and silicon concentrations of $0.04 M$ and $0.03 M$. A problem exists in the use of DLS to monitor the solid particle nucleation when [Al] and [Si] $<0.03 M$, apparently because the limited number of particles that form at low concentrations aggregates and produces relatively large $(>>1-\mu \mathrm{m})$ particles that settle quickly, yielding a system too diluted to scatter sufficient light. For $0.03 \mathrm{M}$ and higher concentrations, the induction time for particle formation can be estimated; the results are given in Table 4. Prior to testing, it was expected that induction times at these lower concentrations would be sufficiently long that the concentration for a 4-h induction time at boiling conditions (approximately $115^{\circ} \mathrm{C}$ ) could be estimated using an activation energy. ${ }^{1}$ However, because the measured induction times at $80^{\circ} \mathrm{C}$ were less than $4 \mathrm{~h}$, it was not possible to estimate the concentration that would result in a 4-h induction time at boiling. [Note that at actual evaporator operating temperatures $\left(120-165^{\circ} \mathrm{C}\right)$, the induction period is expected to be even shorter than that at the refluxing/boiling temperature $\left(115^{\circ} \mathrm{C}\right)$.]
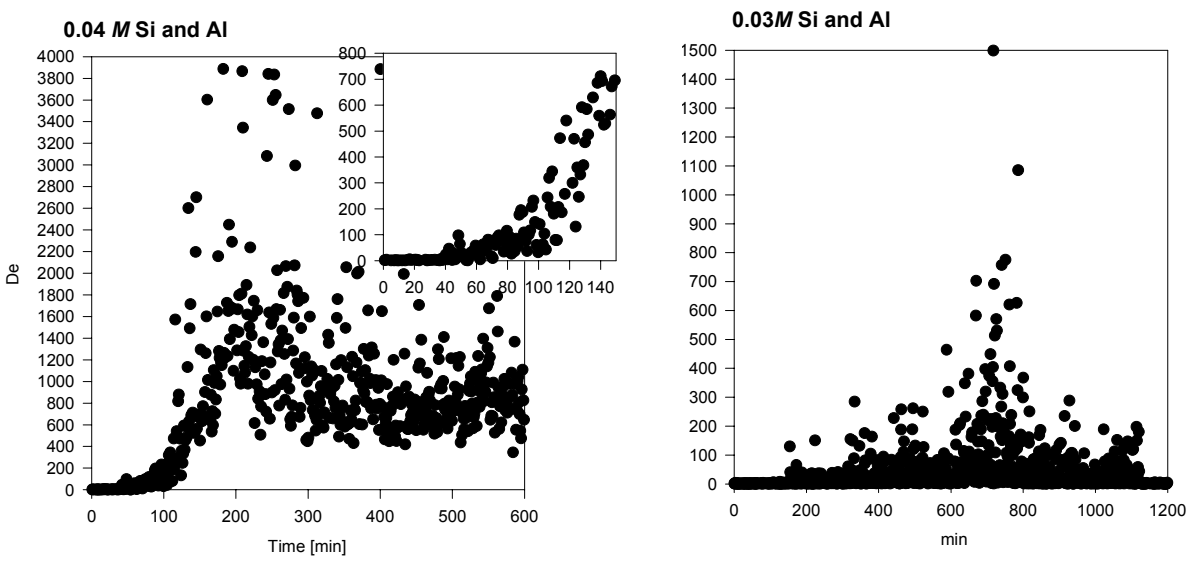

Fig. 3. Dynamic-light-scattering results for $0.04 M$ and $0.03 M$.

Table 4. Induction-time measurements at $80^{\circ} \mathrm{C}$ by dynamic light scattering

\begin{tabular}{cc}
\hline $\begin{array}{c}\text { Concentrations of } \\
\text { Al and } \mathrm{Si}(M)\end{array}$ & $\begin{array}{c}\text { Induction time } \\
(\mathrm{min})\end{array}$ \\
\hline 0.05 & 60 \\
0.04 & 125 \\
0.03 & 155 \\
\hline
\end{tabular}

\subsubsection{PARTICLE FORMATION IN SOLUTION AT REFLUX}

Particle formation in solution at reflux (approximately $115^{\circ} \mathrm{C}$ ) was monitored by DLS performed on periodic samples and by visual observation. Results of an experiment conducted at $0.04 M$ 
aluminum and silicon are shown in Fig. 4 and Table 5. As seen in Fig. 4, the solution remained essentially clear until some period of time in the range of 80 to $110 \mathrm{~min}$. The 110 -min sample was visibly cloudy, while larger, aggregated solids are visible in the 140-min and later samples. The observations are consistent with DLS measurements, which yielded size results near the lower detection limit at 60 and 110 minutes, while the results for samples from 140, 160, 220 and $240 \mathrm{~min}$ indicating particle agglomeration into flocs larger than $1 \mu \mathrm{m}$. The induction time for particle formation appears to be considerably shorter than $4 \mathrm{~h}$ at these concentrations. In addition, once nucleated, the particles aggregate quickly and settle.SEM images of settled solids collected from the 140- and 220-min samples indicate that in addition to crystalline aggregates (Fig. 5), settled solids appear to contain some amorphous materials.

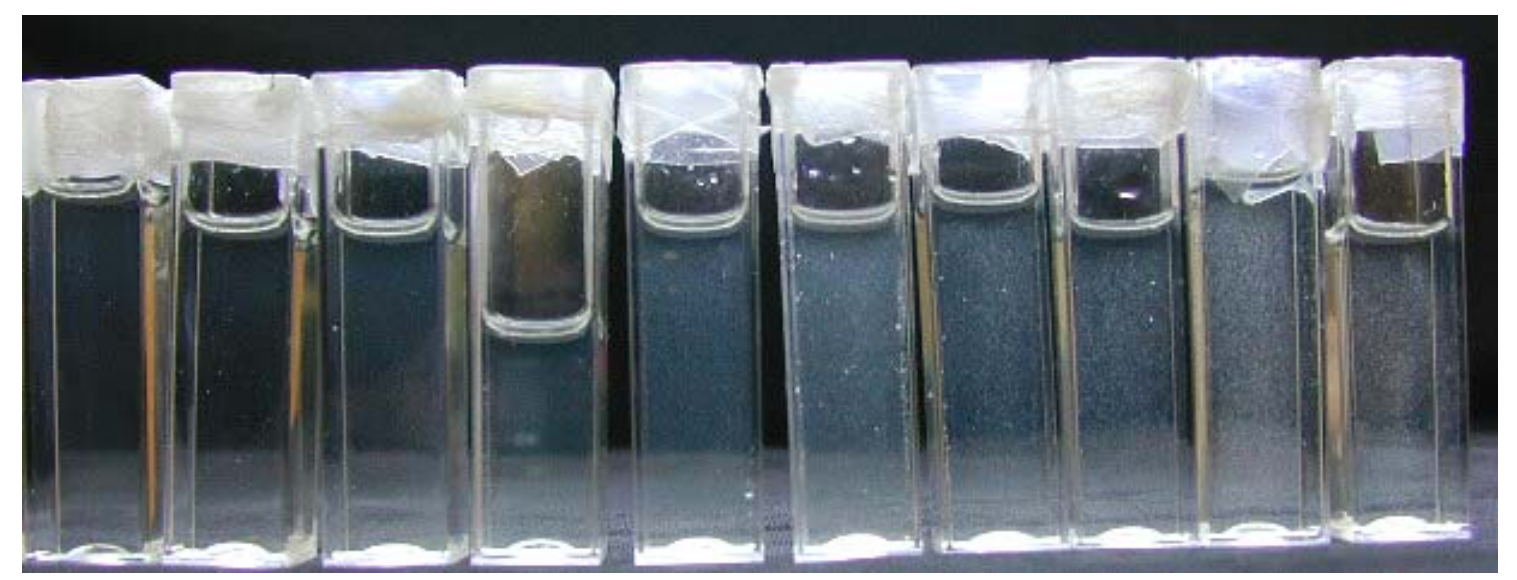

Fig. 4. Samples of refluxed solutions at $[\mathbf{A I}]=[\mathbf{S i}]=\mathbf{0 . 0 4} \boldsymbol{M}$. Time periods (from left) are 40, 60, 80, 110, $140,160,180,200,220$, and $240 \mathrm{~min}$. Samples are at room temperature in photo.

Table 5. Results of particle formation test under reflux at $0.04 M$ aluminum and silicon

\begin{tabular}{ccc}
\hline Time (min) & Visual Observation & DLS result \\
\hline 0 & Clear & $0.2 \mathrm{~nm}$ \\
60 & Clear & $2.1 \mathrm{~nm}$ \\
110 & Nanometer particles & $2.8 \mathrm{~nm}$ \\
140 and greater & Flocculated aggregates & $>1 \mu \mathrm{m}$ \\
\hline
\end{tabular}



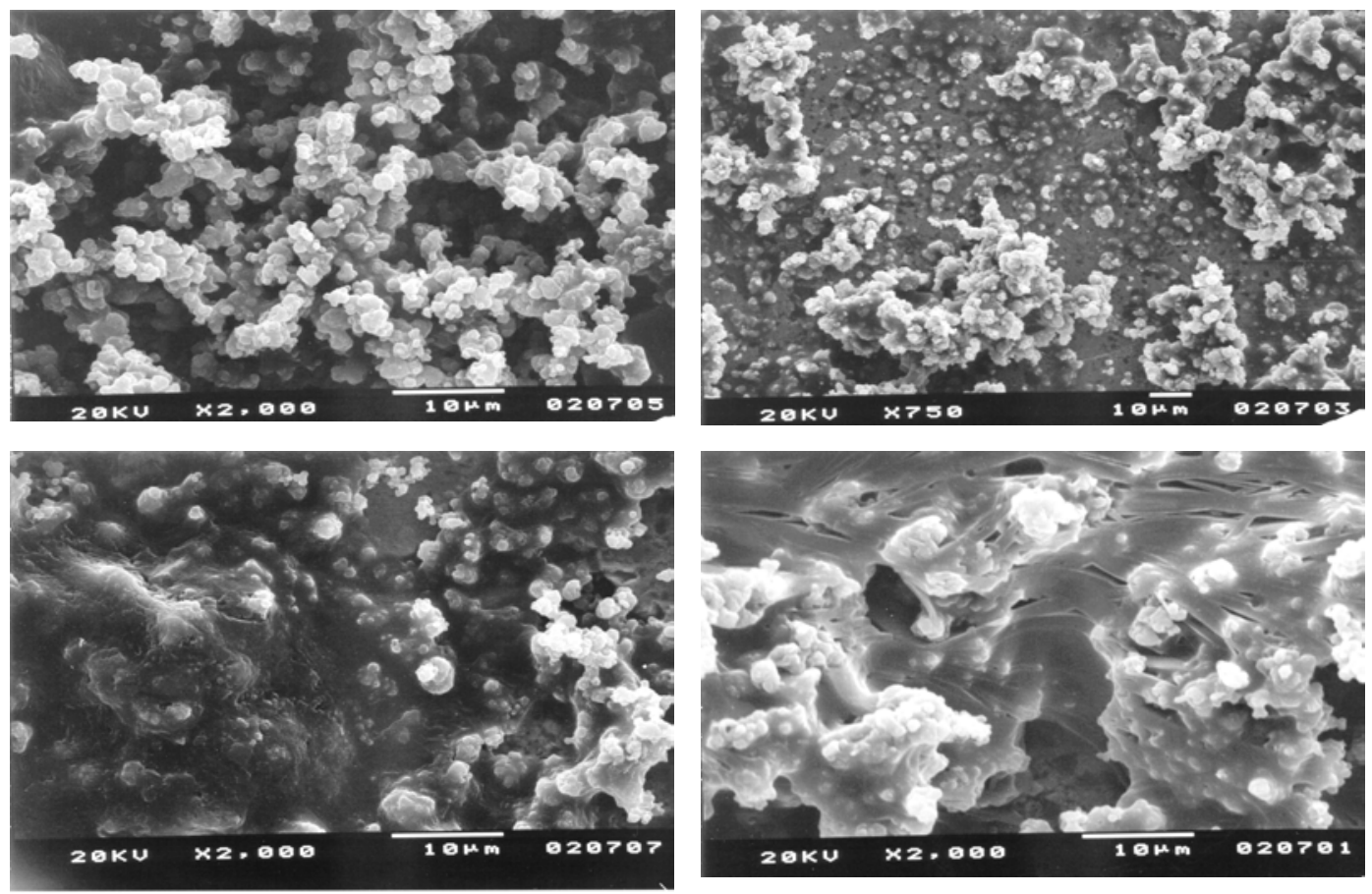

Fig. 5 SEM images of solids from 0.04 $\boldsymbol{M}$ experiment at reflux. At left, $140 \mathrm{~min}$; at right, $220 \mathrm{~min}$.

Photographs of samples collected in experiments at lower concentration levels are shown in Fig. 6. Notable in these results is the finding that many of the samples were clear when hot but turned into bluish, turbid "sol" when cooled to room temperature. The sol could be redissolved by heating to $70^{\circ} \mathrm{C}$. Sols were visible in samples at all tested concentrations $(0.010,0.020,0.025$ and $0.030 \mathrm{M}$ ). True solids that were visible when the solution was hot, and which aggregated and settled, were formed within $4 \mathrm{~h}$ in the $[\mathrm{Al}]=[\mathrm{Si}]=0.025$ and $0.030 \mathrm{M}$ experiments. Therefore, it appears that the threshold for formation of sodium aluminosilicate (NAS) solids in solution under refluxing conditions for $4 \mathrm{~h}$ lies near $0.025 \mathrm{M}$. Analyses were not performed to verify the identity of formed solids.

\subsubsection{DEPOSITION TESTS}

Deposition tests, in which strips of stainless steel foil were exposed to boiling simulant solution for $4 \mathrm{~h}$, were conducted at $[\mathrm{Al}]=[\mathrm{Si}]=0.020,0.025,0.030$, and $0.040 \mathrm{M}$. Fig. 7 shows a photograph of samples from the $0.025 \mathrm{M}$ and $0.040 \mathrm{M}$ experiments. Macroscopic solid deposits were visible on the vertical surfaces of the $0.040 M$ sample, while those from the 0.020 and 

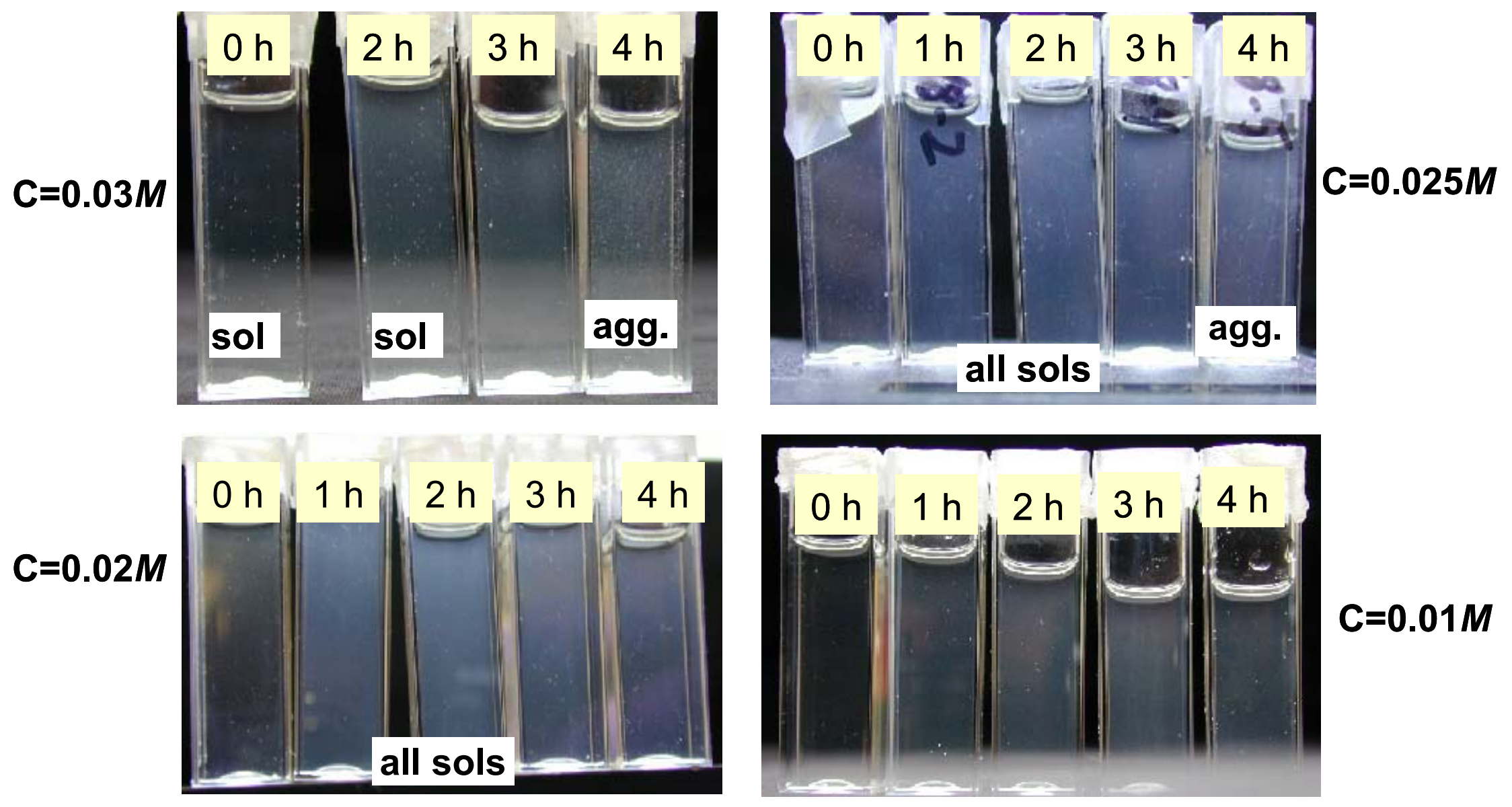

Fig. 6. Samples from reflux experiments at lower supersaturation levels. The label "agg." indicates that when the solution is hot, true solid particles are present that later settle to the bottom; "sol" indicates that solutions were clear when hot but turned into bluish, turbid "sol" when cooled. These sols redissolved with heating to $70^{\circ} \mathrm{C}$. 
$0.0250 M$ experiments appeared shiny and that from the $0.03 M$ experiment appeared slightly less shiny. A thicker solid layer was noted on the top of horizontal surfaces in the 0.03 and 0.04 $M$ samples.

SEM images of the lower horizontal surfaces of the foil samples (Fig. 8) show a significant amount of solids grown on the metal surface in the $0.04 M$ experiment. With decreasing concentration, the surface particles were smaller and the solids covered a smaller portion of the metal surface. At $0.025 \mathrm{M}$, only a very small fraction of the surface was covered with small nuclei, and no deposits were detected at $0.02 \mathrm{M}$. The solids on the horizontal surfaces appear to be heterogeneously grown on the metal surfaces.

Figure 9 shows further details of the deposited solids from the $0.03 \mathrm{M}$ and $0.04 \mathrm{M}$ experiments. The upper-left SEM image in Fig. 9 shows that in some areas, clusters of aggregated crystals were deposited on top of uniformly heterogeneously grown particles. The morphology of the heterogeneously grown particles does not appear to be similar to those from previous studies. ${ }^{1-4}$ Elemental analysis via scanning electron microscopy/energy-dispersive spectroscopy (SEM/EDS) confirmed that the deposited solids are NAS.

In summary, under boiling/refluxing conditions with a [Si]:[Al] ratio of 1, solid particle formation occurs in bulk solution when the product ([Si][Al]), based on concentrations at the start of the experiment, is greater than $\sim 6 \times 10^{-4}$. Also, the growth of solids on the surface of stainless steel coupons seems to correspond to the value of $K_{s p}$; that is, if [Si][Al] $>K_{s p}$, then we observe via SEM examination solid particles heterogeneously grown on the stainless steel surface. Our measured $K_{s p}$ value is consistent with the values previously reported by Wilmarth et al. $\left(3.5 \times 10^{-4} \text { to } 8 \times 10^{-4} M^{2}\right)^{5-7}$.

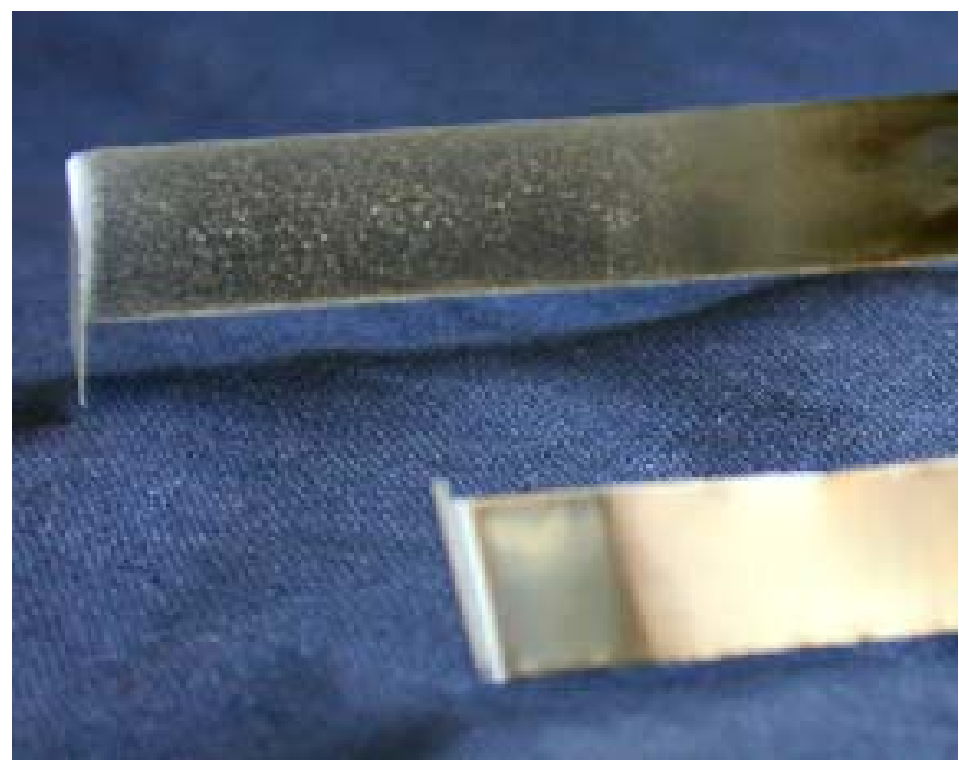

Fig. 7. Samples of stainless steel foil after 4-hour reflux experiments. Front: $0.025 \mathrm{M} \mathrm{Al}$ and $\mathrm{Si}$; back: $0.04 M \mathrm{Al}$ and $\mathrm{Si}$. 


\title{
$0.04 M$ $\mathrm{Al}$ and $\mathrm{Si}$
}

\author{
$0.03 M$ \\ $\mathrm{Al}$ and $\mathrm{Si}$
}

\section{$0.025 M$ $\mathrm{Al}$ and $\mathrm{Si}$}
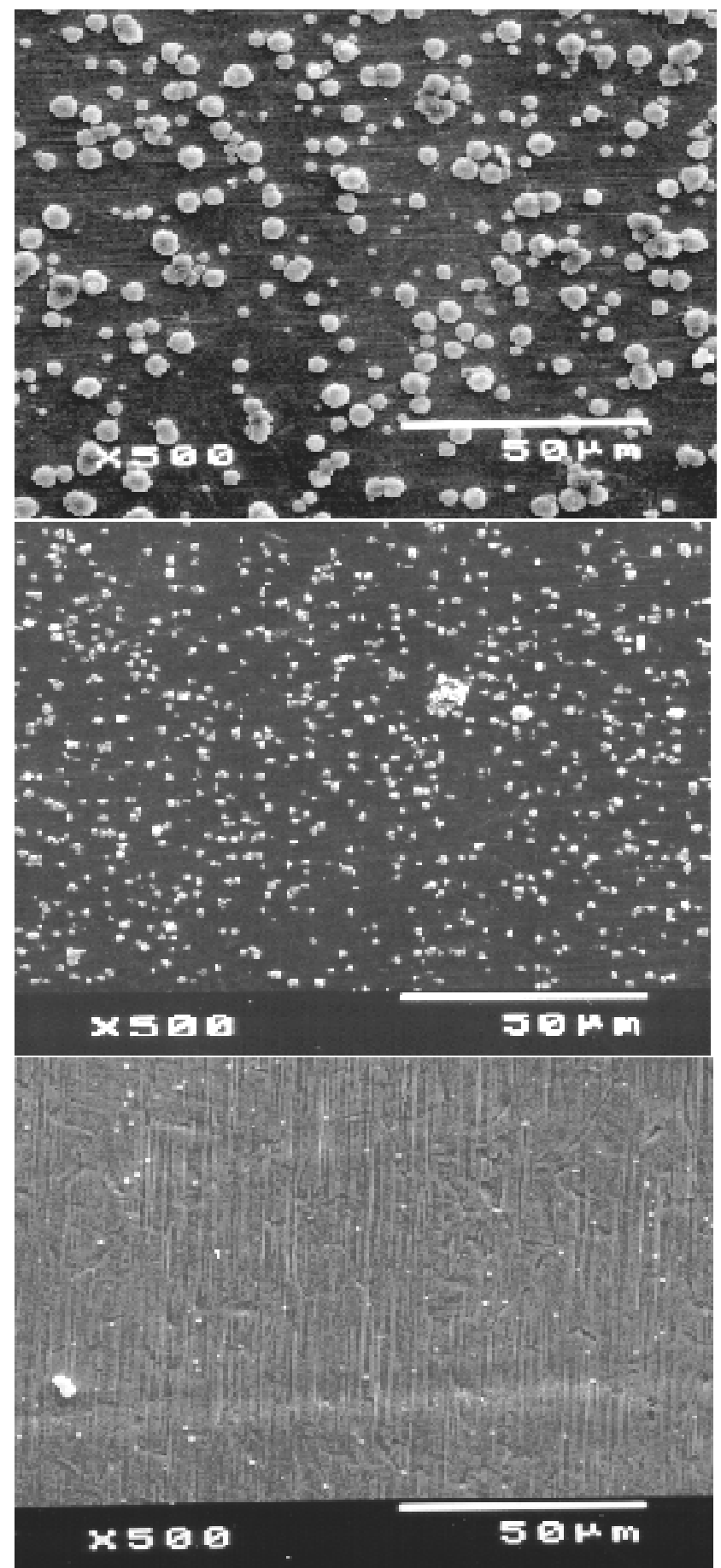

Fig. 8. SEM images of metal surfaces from 4-h reflux deposition tests. From the top: the values of the product ([Al] [Si]) at the start of the experiment are $1.6 \times 10^{-3}, 9.0 \times 10^{-4}$, and $6.3 \times 10^{-4} M^{2}$. 

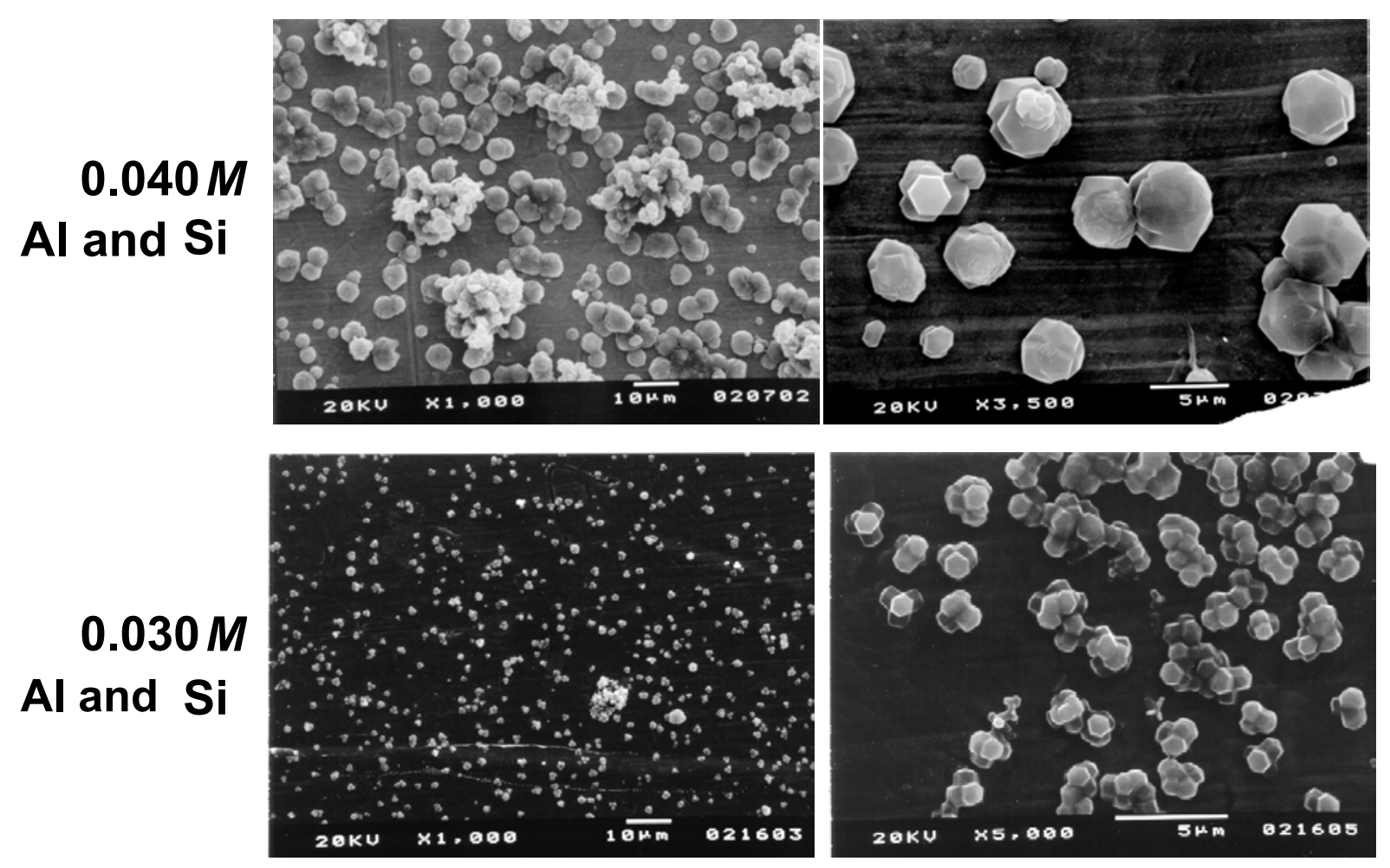

Fig. 9. SEM images of solids deposited on metal surfaces during 4-h refluxed deposition tests.

\subsection{RESULTS FOR EXPERIMENT SET TWO}

Additional deposition tests (beyond the original task plan) were conducted under evaporation([A1]:[Si] $>1$, with volume reduction) and using the following two conditions:

- $2 \mathrm{H}$ evaporator simulants and resulting mixture compositions, and

- $3 \mathrm{H}$ evaporator simulants.

In Sects. 3.2.1 and 3.2.2, we report only the studies of solid growth/deposition by SEM examination of the bottom surface of stainless steel coupon after exposure to the evaporated liquid.

\subsubsection{Tests with 2H Evaporator Simulants and Resulting Mixture Compositions}

Figure 10 summarizes the SEM examination of all the coupon surfaces after three degrees of evaporation (i.e., 66, 80, and 90 vol \%) using three liquid compositions (i.e., 26:74, 39:61, and 63:37). Under nearly all conditions (regardless of the degree of evaporation and liquid composition), micrometer-sized particles were observed on sample coupon surfaces due to a heterogeneous growth mechanism. SEM/EDS elemental analysis confirmed that the discrete solid particles on the metal surfaces are NAS. It should be noted that the 


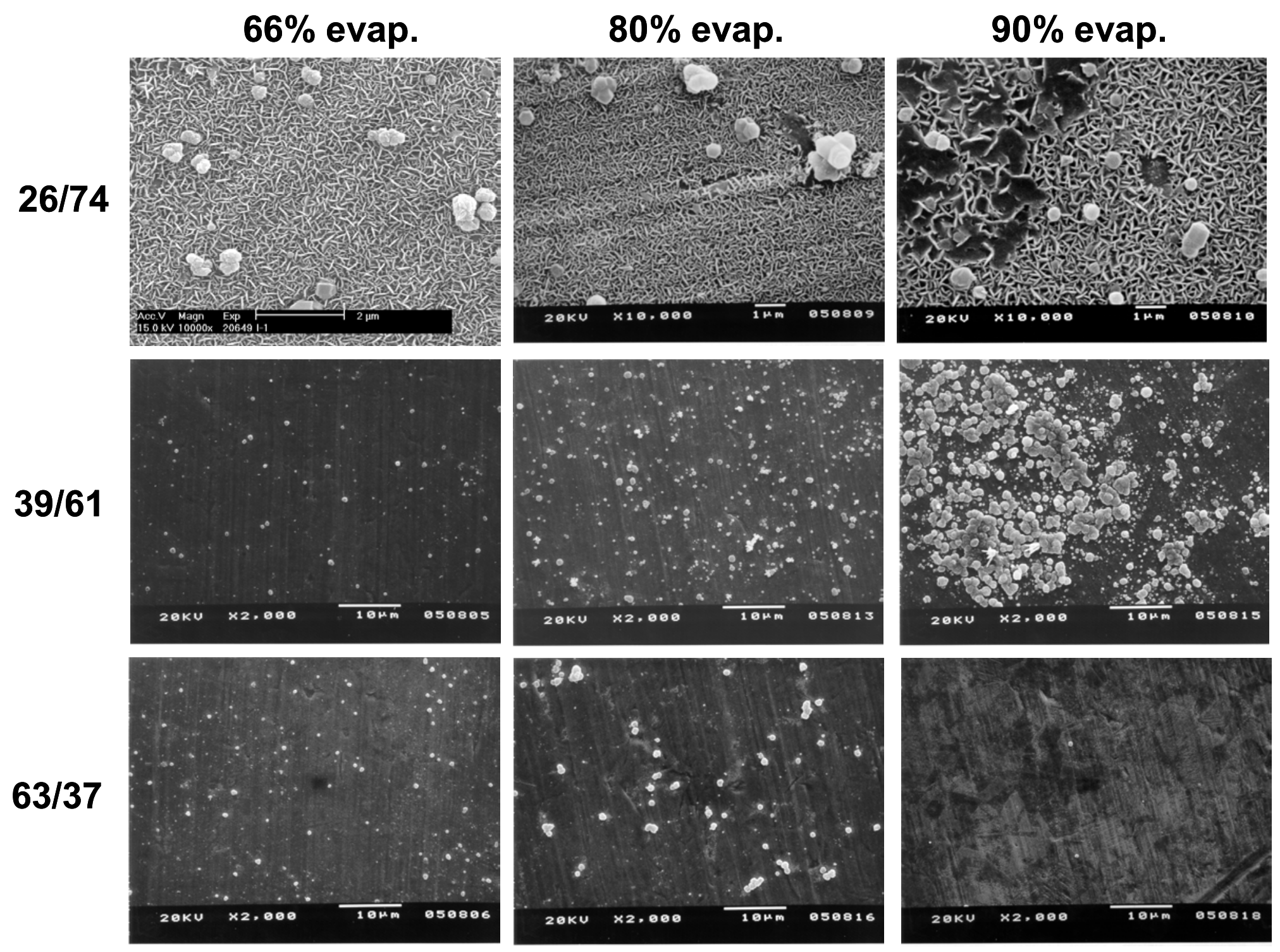

Fig. 10. SEM images of solids on the surfaces of stainless steel coupons immersed in solutions during DWPF recycle evaporation tests. The values to the left of the figure $(26: 74,39: 61$, and 63:37 refer to ratios of Tank 43 simulant to DWPF recycle stimulant in the solution mixture (volume percent). 
background worm-like surface in the top row of SEM images is the result of accidental electrochemical corrosion of the stainless steel surfaces from the conductance-based levelsensing device used.

\subsubsection{Tests with $3 H$ Evaporator Simulants}

The purpose of these scooping tests was to see if any solids formed on the coupon surfaces under various levels of evaporation. Under all evaporation conditions (i.e., equivalent to 0,32 , and 42 vol \% evaporation of $3 \mathrm{H}$ feed), microscopic particles and patches of solid were observed on the stainless-steel coupon surfaces (Fig. 11). It appears that with an increasing degree of evaporation, more surface particles were heterogeneously grown on the surfaces. SEM/EDS elemental analysis confirmed that the patches of nanosized $(<100 \mu \mathrm{m})$ solid particles on the metal surfaces are NAS.

For the $32 \%$ coupon sample, some visible thick solids were found on one side of the bottom surface of coupon. Figure 12 shows the solids in this local area under different levels of magnification. This suggests that macroscopic, as well as microscopic, solids could form on the metal surface during evaporation.

\section{DISCUSSION}

These scoping tests were undertaken to estimate the supersaturation level above which aluminosilicate solids form in solution and on steel surfaces under temperature and residence time conditions similar to those of evaporator operation. The results of this work indicated that the formation of solids in solution is thermodynamically and kinetically favorable at concentrations as low as $K_{s p}=[\mathrm{Al}][\mathrm{Si}]=6 \times 10^{-4} M^{2}$. At the tested concentrations below $0.025 \mathrm{M}$ aluminum and silicon, no solids were detected at elevated temperature; however, it is notable that bluish sols formed upon cooling of the solutions (although the sol could be dissolved by heating to $70^{\circ} \mathrm{C}$ ).

The experiments in which samples of steel were placed in the (1) boiling solutions for $4 \mathrm{~h}$ or (2) heated solutions evaporated to desired volume reductions may provide more pertinent information regarding the potential for solids deposition on evaporator surfaces. Macroscopic amounts of solids were deposited at $0.04 M$ aluminum and silicon. Solids also grew heterogeneously on steel surfaces in smaller amounts at concentrations as low as $0.025 \mathrm{M}$ aluminum and silicon. The results obtained to date suggest that the $K_{s p}$ above which solids may form under evaporator conditions may be $6 \times 10^{-4} M^{2}($ when $[\mathrm{Si}]:[\mathrm{Al}]=1)$.

For comparison of the results with those from other studies of NAS formation, data from the current deposition tests and some derived quantities are presented in Table 5 and described in the paragraphs that follow. The product [Al] [Si] for each experiment under reflux conditions is listed. These data compare favorably with values presented by Wilmarth et al. ${ }^{5-7}$, which have yielded $K_{s p}$ values on the order of $3.5 \times 10^{-4} M^{2}$ to $8 \times 10^{-4} M^{2}$. Additionally, the table presents the values for quantities derived by Jantzen and Laurinat ${ }^{8}$ to represent an ion product $Q(N A S)$ for formation of aluminosilicate cage structures NAS gel. Two different equations for $Q(N A S)$ are used, including the simplified equation that does not include the sodium concentration. 

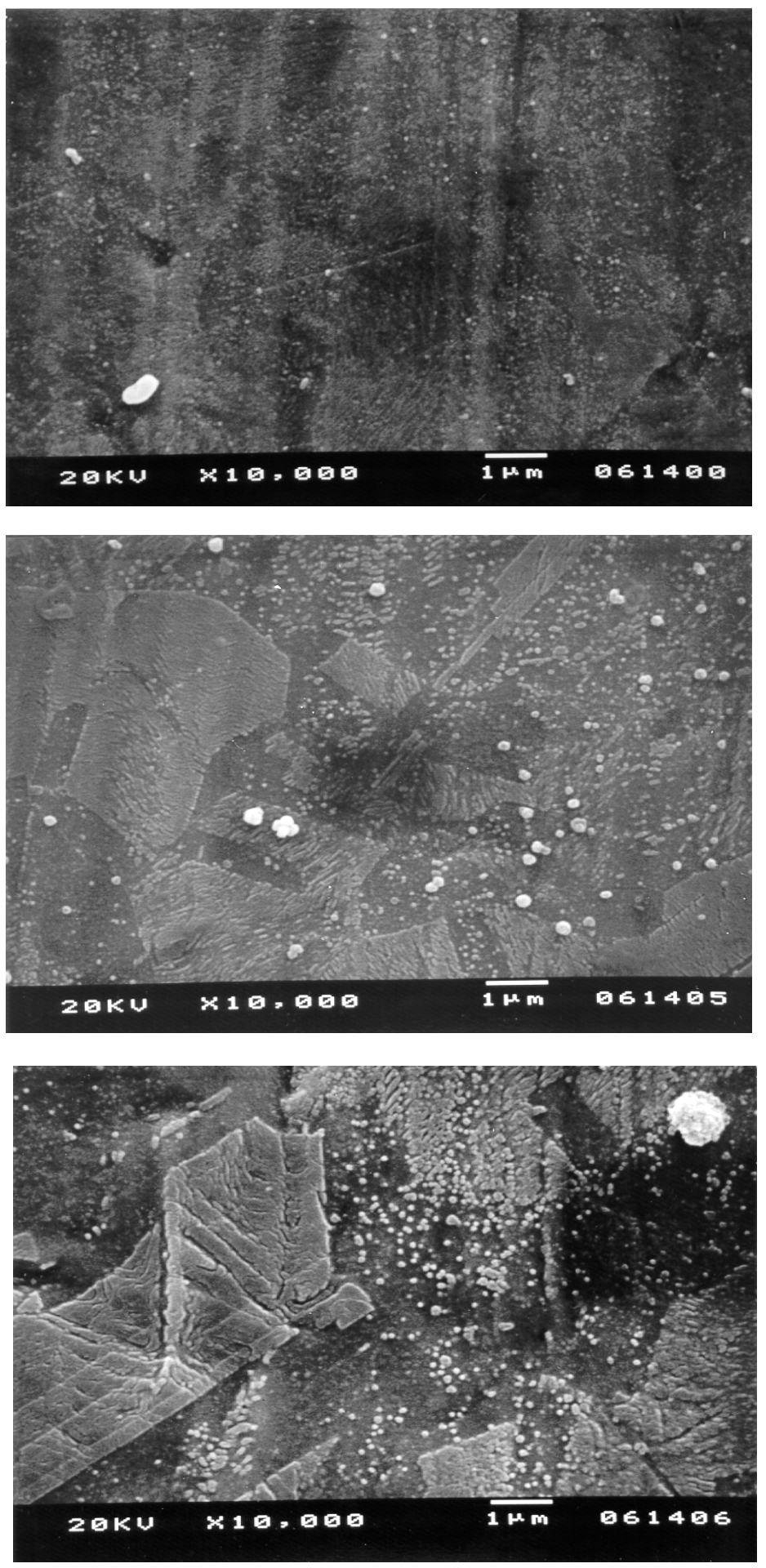

Fig. 11. SEM images of solids on the surfaces of stainless steel coupons immersed in solutions during $3 \mathrm{H}$ evaporation tests. From top: 0 , 32, and $42 \%$ evaporation of $3 \mathrm{H}$ feed. 

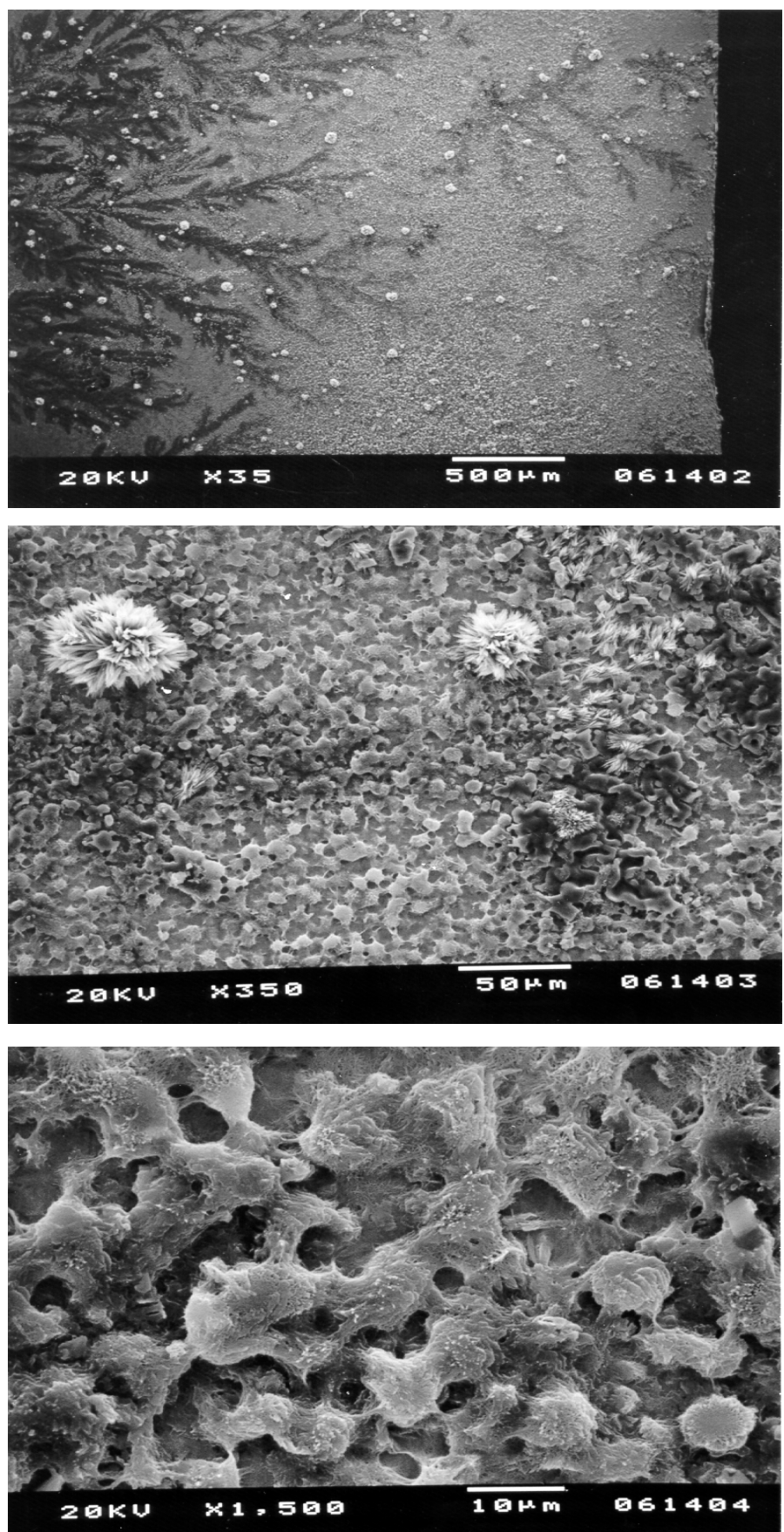

Fig. 12. SEM images of macroscopic solids deposits from $32 \%$ evaporation of $3 \mathrm{H}$ simulant. Images are in order of increasing magnification from top to bottom. 
Table 6. Summary of Deposition Experiments

Concentrations (in M) are listed for start of experiment; concentrations multiplied by 0.6 for Q(NAS) calculation

Q(NAS) calculated from Eqns. 31 and 34 of WSRC-TR-2000-00293 (Ref. 8). Approximate apparent operational limits: eqn 31: - 29; eqn 34:-44

4-h Reflux Tests. Note: no volume reduction

\begin{tabular}{|c|c|c|c|c|c|c|c|c|c|}
\hline$[\mathrm{Na}]$ & {$[\mathrm{Al}]$} & {$[\mathrm{Si}]$} & $\mathrm{Al} / \mathrm{Si}$ & {$[\mathrm{OH}]$} & $\begin{array}{c}{[\mathrm{A} 1][\mathrm{Si}]} \\
\text { based on initial } \\
\text { concentrations }\end{array}$ & Q(NAS) & Q(NAS) & $\begin{array}{c}\text { Microscopic solids } \\
\text { on coupon? } \\
\text { (SEM) }\end{array}$ & $\begin{array}{c}\text { Macroscopic } \\
\text { solids on } \\
\text { coupon? (visual) }\end{array}$ \\
\hline 9.0 & 0.040 & 0.040 & 1 & 6.0 & $1.60 \mathrm{E}-03$ & -36.7 & -45.5 & Yes & Yes \\
\hline 9.0 & 0.030 & 0.030 & 1 & 6.0 & $9.00 \mathrm{E}-04$ & -39.9 & -48.7 & Yes & No \\
\hline 9.0 & 0.025 & 0.025 & 1 & 6.0 & $6.25 \mathrm{E}-04$ & -42.0 & -50.8 & Yes & No \\
\hline 9.0 & 0.020 & 0.020 & 1 & 6.0 & $4.00 \mathrm{E}-04$ & -44.5 & -53.3 & No & No \\
\hline
\end{tabular}

\section{DWPF Recycle Evaporation Tests}

\begin{tabular}{|c|c|c|c|c|c|c|c|c|c|}
\hline $\begin{array}{l}\text { Volume } \\
\text { Reduction }\end{array}$ & {$[\mathrm{Na}]$} & {$[\mathrm{Al}]$} & {$[\mathrm{Si}]$} & $\mathrm{Al} / \mathrm{Si}$ & {$[\mathrm{OH}]$} & Q(NAS) & $\mathrm{Q}(\mathrm{NAS})$ & $\begin{array}{l}\text { Microscopic solids } \\
\text { on coupon? } \\
\text { (SEM) }\end{array}$ & $\begin{array}{c}\text { Macroscopic } \\
\text { solids on } \\
\text { coupon? (visual) }\end{array}$ \\
\hline $26 / 74$ mix & 1.65 & 0.0182 & 0.0019 & 10 & 0.89 & & & & \\
\hline $66 \%$ & & & & & & -48.2 & -53.7 & Yes & No \\
\hline $80 \%$ & & & & & & -40.8 & -49.1 & Yes & No \\
\hline $90 \%$ & & & & & & -31.2 & -43.1 & Yes & No \\
\hline 39/61 mix & 1.98 & 0.0273 & 0.0018 & 15 & 1.09 & & & & \\
\hline $66 \%$ & & & & & & -46.0 & -52.5 & Yes & No \\
\hline $80 \%$ & & & & & & -38.6 & -47.9 & Yes & No \\
\hline $90 \%$ & & & & & & -29.0 & -41.8 & Yes & No \\
\hline $63 / 37$ mix & 2.58 & 0.0441 & 0.0017 & 26 & 1.45 & & & & \\
\hline $66 \%$ & & & & & & -43.2 & -51.1 & Yes & No \\
\hline $80 \%$ & & & & & & -35.8 & -46.5 & Yes & No \\
\hline $90 \%$ & & & & & & -26.2 & -40.4 & Yes & No \\
\hline
\end{tabular}

\section{H Evaporation Test}

\begin{tabular}{|c|c|c|c|c|c|c|c|c|c|c|c|c|}
\hline & $\begin{array}{l}\text { Evaporation of } \\
\text { Tank } 30 \text { feed }\end{array}$ & $\begin{array}{c}{[\mathrm{Na}]} \\
M\end{array}$ & $\begin{array}{c}{[\mathrm{Al}]} \\
\boldsymbol{M}\end{array}$ & $\begin{array}{c}{[\mathbf{S i}]} \\
M\end{array}$ & $\begin{array}{c}{\left[\mathrm{NO}_{3}\right]} \\
M\end{array}$ & $\begin{array}{c}{\left[\mathrm{NO}_{2}\right]} \\
M\end{array}$ & $\underset{M}{[\mathrm{OH}]}$ & $\begin{array}{c}[\mathbf{A}]]^{*}[\mathrm{Si}] \\
\left.\boldsymbol{M}^{2}\right]\end{array}$ & $Q(N A S)$ & $Q(N A S)$ & $\begin{array}{l}\text { Microscopic } \\
\text { solids on coupon? } \\
\text { (SEM) }\end{array}$ & $\begin{array}{l}\text { Macroscopic solids } \\
\text { on coupon? } \\
\text { (visual) }\end{array}$ \\
\hline average Tank 30 & $0 \%$ & 13.7 & 0.93 & 0.0024 & 1.29 & 1.79 & 9.58 & $2.23 \mathrm{E}-03$ & & & & \\
\hline starting solution & $-14 \%$ & 12.0 & 0.80 & 0.0021 & 1.20 & 1.51 & 8.49 & $1.70 \mathrm{E}-03$ & & & & \\
\hline sample 1 & $0 \%$ & & & & & & & & -36.5 & -47.5 & No & No \\
\hline sample 2 & $32 \%$ & & & & & & & & -31.2 & -44.2 & Yes & Yes \\
\hline sample 3 & $42 \%$ & & & & & & & & -29.0 & -42.8 & Yes & No \\
\hline
\end{tabular}




$$
\begin{gathered}
Q(N A S)=12 \log _{10}[\mathrm{Al}]+14 \log _{10}[\mathrm{Si}]+12 \log _{10}[\mathrm{Na}]-6 \log _{10}[\mathrm{OH}] \\
\text { Simplified } Q(N A S)=12 \log _{10}[\mathrm{Al}]+14 \log _{10}[\mathrm{Si}]-6 \log _{10}[\mathrm{OH}]
\end{gathered}
$$

To compare the data obtained in the ORNL-conducted experiments with those of Fig. 49 of Ref. 8, the calculated concentrations used in the experiments must be adjusted by multiplying by 0.6 to account for the assumed $40 \%$ evaporation in Fig. 49 . The adjusted $Q$ (NAS) values are more negative than the $\sim-29$ value presented in Ref. 8, suggesting that solutions less concentrated than the proposed control limit may deposit solids under some conditions. The possibility for solids formation with solutions less concentrated than the control limit is most vividly illustrated by the deposition experiment conducted with $0.04 \mathrm{M}$ of both aluminum and silicon, which obviously deposited solids (Fig. 7); the proposed control limit of $2.3 \times 10^{-3} \mathrm{M}^{2}$ corresponds to $0.048 \mathrm{M}$ aluminum and silicon.

The results of the batch refluxing deposition experiments seem to agree with the experimental limit for cancrinite by Wilmarth and Walker ${ }^{5-7}$. Little growth of surface solids was observed, except for the $0.04 M 1: 1$ experiment and the patch of macroscopic solids in the $3 \mathrm{H}$ experiment ( $32 \%$ sample). Indeed, it is possible to form "surface" solids at concentrations more dilute than those predicted by the operational limit noted by Jantzen and Laurinat ${ }^{8}$; however, it is not clear, particularly in light of the historical plant operational data, whether the solids formation detected in these laboratory batch experiments is of concern for setting operational limits for the evaporators. Additional testing, including tests with continuous-flow evaporators, is recommended for better evaluation of the potential for formation of macroscopic solids during evaporation. It is also important to know the kinetics of heterogeneous solid growth under diluted-concentration conditions.

The experiments in this report were conducted under a limited temperature range and with simulants of specific compositions; it is uncertain whether the results are applicable to other temperatures and compositions. The apparent solubility product $\mathrm{K}_{\mathrm{sp}}=[\mathrm{Si}][\mathrm{Al}]$ determined in the refluxing experiments is based on the initial concentrations of simulant solutions above which microscopic NAS solids (observed by SEM) grow on the surfaces of stainless steel foils at the boiling temperature $\left(\sim 115^{\circ} \mathrm{C}\right)$. Also, $Q(N A S)$ values that were correlated with the presence/absence of surface NAS solids in the evaporator tests were for experiments conducted near the boiling temperature of the mixture, which varied throughout the evaporation process. The equilibrium values of $K_{s p}$ appear to depend on the temperatures of the solutions. Data in a recent report ${ }^{9}$ suggest an increased NAS solubility with increasing temperature; the solubilities of the NAS phases studied are also sensitive to other parameters such as hydroxide content. Therefore, $K_{s p}$ and/or acceptable $Q(N A S)$ values at higher temperatures are best determined experimentally rather than attempting to extrapolate data from these tests. 


\section{REFERENCES}

1. Hu, M. Z.-C., D. W. DePaoli, and D. T. Bostick, Dynamic Particle Growth Testing - Phase I Studies, ORNL/TM2001/100, July 2001.

2. Dworjanyn, L. O., Simulated Aluminosilicate Formation and 2H-Evaporator Scaling (U), WSRC-RP-2001-00779, August 2001.

3. Rosencrance, S., D. Herman, and D. Healy, Formation and Deposition of Aluminosilicates in Support of the 2H Evaporator Fouling Program (U) WSRC-TR-2001-00464, October 2001.

4. Mattus, A. J., C. H. Mattus, and R. D. Hunt, Investigation into the Control and Kinetics of Aluminosilicate Formation on Stainless Steel Surfaces at $100^{\circ} \mathrm{C}$, ORNL/TM-2002/47, April 2002.

5. Wilmarth, W. R., D. D. Walker, and S. D. Fink, Sodium Aluminosilicate Formation in Tank 43 Simulants, WSRC-TR-97-00389, November 1997.

6. Wilmarth, W. R., J. T. Mills, V. H. Dukes, and R. C. Sullivan, Characterization of Surface and Variable Depth Samples from the $3 H$ Evaporator Feed (32H) and Drop (3OH) Tanks Re-Baseline of Silicon Concentration and Aluminosilicate Formation, WSRC-TR-200100514 , October 2001.

7. Wilmarth, W. R., J. T. Mills, V. H. Dukes, and F. F. Fondeur, Tank $38 H$ Desilication Study, WSRC-TR-2001-00582, November 2001.

8. Jantzen, C. M., and J. E. Laurinat, Thermodynamic Modeling of the SRS Evaporators: Part I. The 2H and $2 F$ Systems (U), WSRC-TR-2000-00293, November 2001.

9. S. W. Rosencrance, Interim Report from the University of South Australia Subcontract GA0083, SRT-LWP-2002-00060, June 24, 2002. 


\section{Appendix. Solution Preparation}

A solution containing the sodium salts of the primary anions in the evaporator (nitrite, nitrate, and hydroxide) was prepared as the base simulant. Additionally, concentrated aluminum- and silicon-containing solutions were prepared in the same chemical matrix, such that the concentrates could be mixed in known volumes to achieve testing solutions containing final concentrations of aluminum and silicon ranging from 0 to $0.05 \mathrm{M}$ were filtered using PTFE filters prior to use.

Solution Preparation: (1) The simulant was prepared by first dissolving solid $\mathrm{NaOH}$ in nanopure water. Once the solution was cooled to room temperature, sodium nitrate was dissolved, followed by sodium nitrite. The composition was:

$\begin{array}{ll} & \mathrm{mol} / \mathrm{L} \\ \text { Total } \mathrm{Na}^{+} & 9 \\ \text { Total } \mathrm{OH}^{-} & 6 \\ \text { Total } \mathrm{NO}_{3}{ }^{2-} & 1.5 \\ \text { Total } \mathrm{NO}_{2}{ }^{-} & 1.5\end{array}$

(2) Aluminum nitrate solution was prepared by first dissolving solid $\mathrm{NaOH}$ in nanopure water. Once the solution cooled to room temperature, aluminum nitrate $\left[\mathrm{Al}\left(\mathrm{NO}_{3}\right)_{3} \theta 9 \mathrm{H}_{2} \mathrm{O}\right]$ was added and dissolved. After complete dissolution of the aluminum salt, sodium nitrate was dissolved, followed by sodium nitrite. The prepared aluminum concentrate was:

$\begin{array}{ll} & \underline{\mathrm{mol} / \mathrm{L}} \\ \text { Total } \mathrm{Na}^{+} & 8.4 \\ \text { Total } \mathrm{OH}^{-} & 6 \\ \text { Total } \mathrm{NO}_{3}{ }^{2-} & 1.5 \\ \text { Total } \mathrm{NO}_{2}{ }^{-} & 1.5 \\ \text { Total } \mathrm{Al}^{3+} & 0.2\end{array}$

(3) Sodium metasilicate solution was prepared by first dissolving solid $\mathrm{NaOH}$ in nanopure water. Once the solution cooled to room temperature, sodium metasilicate $\left[\mathrm{Na}_{2} \mathrm{SiO}_{3} \theta 9 \mathrm{H}_{2} \mathrm{O}\right]$ was added and dissolved. After complete dissolution of the metasilicate salt, sodium nitrate was dissolved, followed by sodium nitrite. The prepared silicon concentrate composition was:

$\begin{array}{ll} & \underline{\mathrm{mol} / \mathrm{L}} \\ \text { Total } \mathrm{Na}^{+} & 9.4 \\ \text { Total } \mathrm{OH}^{-} & 6 \\ \text { Total } \mathrm{NO}_{3}{ }^{2-} & 1.5 \\ \text { Total } \mathrm{NO}_{2}{ }^{-} & 1.5 \\ \text { Total Si } & 0.2\end{array}$

